\title{
Meta-analysis on insulin treatment for type 2 diabetes: rushed conclusions? Reply to Wägner AM, Mauricio D [letter]
}

\author{
A. J. Farmer • D. S. Lasserson • R. R. Holman
}

Received: 23 December 2009/Accepted: 23 December 2009/Published online: 23 February 2010

(C) Springer-Verlag 2010

\section{Abbreviation \\ 4T Treating to Target in Type 2 Diabetes}

To the Editor: We welcome the opportunity to comment on the issues raised by Wägner and Mauricio [1] concerning our systematic review [2] of different types of insulin treatment for patients with type 2 diabetes. Many of the issues raised in their letter were addressed in the review. The limited number of trials providing data for each comparison, and consequently the difficulty in drawing firm conclusions, is clearly stated in the Discussion. Eight of 22 trials scored five out of a possible six points in the modified assessment for potential bias; and the database search for the review was carried out in October 2008, 10 months before the results of the Treating to Target in Type 2 Diabetes (4-T) study 3 year data [3] were known. In carrying out this review, our intention was to report potential differences between insulin regimens used routinely in the treatment of type 2 diabetes. We observed smaller reductions in $\mathrm{HbA}_{1 \mathrm{c}}$ levels in patients using basal regimens compared

A. J. Farmer · D. S. Lasserson $(\bowtie)$

Division of Public Health and Primary Care,

University of Oxford,

Rosemary Rue Building, Old Road Campus, Headington,

Oxford OX3 7LF, UK

e-mail: daniel.lasserson@dphpc.ox.ac.uk

\section{R. R. Holman}

Diabetes Trials Unit, Oxford Centre for Diabetes,

Endocrinology and Metabolism,

University of Oxford,

Oxford, UK with those using prandial or biphasic regimens. Lower insulin doses for patients using basal regimens were observed, but this does not imply that more aggressive titration would have resulted in more favourable outcomes at 1 year.

We note the suggestion that the time-point in the progression of diabetes may influence the choice of insulin regimen. Given the benefit of minimising the risk of hypoglycaemia, as demonstrated by the 4-T trial [3], prompt response to oral therapy inadequacy with basal insulin should be recommended. That study has not, to date, provided evidence of benefit for individualising therapy based on markers of disease progression, although the different impact of the regimens reported by the 4-T trial may lead individual patients to prefer one therapy to another.

Duality of interest R. R. Holman is chief investigator on the Treating to Target in Type 2 Diabetes (4-T) study and has received research support, fees for advisory board membership and lectures from Novo Nordisk, Eli Lilly and sanofi-aventis. A. J. Farmer is a coinvestigator on the 4-T study. D. S. Lasserson declares that there is no duality of interest associated with this manuscript.

\section{References}

1. Wägner AM, Mauricio D (2010) Meta-analysis on insulin treatment for type 2 diabetes: rushed conclusions? Diabetologia. doi:10.1007/ s00125-010-1678-z

2. Lasserson DS, Glasziou P, Perera R, Holman RR, Farmer AJ (2009) Optimal insulin regimens in type 2 diabetes mellitus: systematic review and meta-analyses. Diabetologia 52:1990-2000

3. Holman RR, Farmer AJ, Davies MJ, Levy JC (2009) Three-year efficacy of complex insulin regimens in type 2 diabetes. $\mathrm{N}$ Engl $\mathrm{J}$ Med 361:1736-1747 